Arq. Bras. Med. Vet. Zootec., v.66, n.3, p.870-878, 2014

\title{
Variáveis agronômicas e químicas e degradabilidade ruminal da cana-de-açúcar
}

[Agronomic and chemical variables and sugarcane ruminal degradability]

\author{
C.B. Teixeira ${ }^{1}$, M.H. Ramos $^{1}$, J.F. Santos ${ }^{1}$, M.L. Chaves $^{1}$, L.L. Bitencourt ${ }^{1}$, R.A.N. Pereira ${ }^{2}$, \\ M.A.P. Ramalho ${ }^{1}$, M.N. Pereira ${ }^{1 *}$ \\ ${ }^{1}$ Universidade Federal de Lavras - Lavras, MG \\ ${ }^{2}$ Empresa de Pesquisa Agropecuária de Minas Gerais - Lavras, MG
}

\begin{abstract}
RESUMO
Objetivou-se avaliar a variabilidade do valor nutritivo entre cultivares de cana-de-açúcar, estimar a correlação entre digestibilidade e produtividade da planta e definir características químicas e agronômicas mais correlacionadas ao valor nutritivo. Vinte cultivares de cana-de-açúcar foram cultivados em delineamento em blocos ao acaso, com quatro repetições, em Campos, RJ, Brasil. As plantas foram colhidas com Brix superior a $18 \%$, a partir de 370 dias do corte da segunda soca. Características agronômicas e químicas e as degradabilidades ruminais in situ da FDN e da MS foram avaliadas. A produtividade foi $21,2 \pm 5,7 \mathrm{t}$ de MS/ha, e a degradabilidade ruminal da MS (DEG MS) foi 57,1 $\pm 2,6 \%$ do incubado (média $\pm D P$ ). A degradabilidade ruminal da FDN foi $19,8 \pm 2,42 \%$ do incubado. Nenhuma variável avaliada foi correlacionada à degradabilidade da FDN $(P>0,10)$. Obter cultivares que conciliam alta produtividade com alta DEG MS é viável, pois a correlação tanto fenotípica quanto genética entre esses caracteres foi pequena. $\mathrm{A} \mathrm{h}^{2}$ para a DEG MS foi superior a $85 \%$. Variáveis indiretamente correlacionadas à DEG MS tiveram menor $\mathrm{h}^{2}$ que o desta variável. Canas com baixo conteúdo de fibra, com colmos curtos e com alta relação entre colmos e folhas, foram mais digestíveis.
\end{abstract}

Palavras-chave: bovino, digestibilidade, fibra, produtividade

\begin{abstract}
The objective was to evaluate the variability of nutritive value among sugarcane cultivars, to estimate the correlation between plant digestibility and productivity, and to define agronomical and chemical traits most correlated with nutritive value. Twenty sugarcane cultivars were cultivated in a completely randomized block design with four replicates in Campos, RJ, Brazil. Plants were harvested when the Brix was superior to $18 \%$, starting at 370 days after the second ratoon cut. Agronomical and chemical traits and the ruminal NDF and DM in situ degradability were evaluated. Productivity was $21.2 \pm 5.7 t$ of DM/ha and ruminal DM degradability (DM DEG) was $57.1 \pm 2.6 \%$ of incubated (mean $\pm S D)$. Ruminal NDF degradability was $19.8 \pm 2.42 \%$ of incubated, and none of the variables evaluated were correlated to the NDF degradability $(P>0.10)$. Obtaining cultivars that conciliate high productivity to high digestibility is feasible, since the phenotypic and the genetic correlation between these traits were low. The estimated $h^{2}$ for the DM DEG was superior to $85 \%$. Variables indirectly correlated to the digestibility had smaller $h^{2}$ than the one for this variable. Sugarcane with low fiber content, short stalk length and high stalk to leaves ratio were more digestible.
\end{abstract}

Keywords: bovine, digestibility, fiber, productivity

\section{INTRODUÇÃO}

O uso da cana-de-açúcar como opção forrageira para alimentação de ruminantes em condições tropicais é uma tecnologia conhecida de longa data (Preston e Leng, 1980). Essa forrageira, quando incluída em dietas formuladas para alto desempenho animal, tem mostrado ser capaz de suportar boa eficiência zootécnica de animais especializados em produção de leite (Corrêa et

Recebido em 2 de julho de 2012

Aceito em 18 de novembro de 2013

*Autor para correspondência (corresponding author)

E-mail: mpereira@ufla.br 
al., 2003). A cana tem a capacidade de conciliar a alta produção de MS por unidade de área com o alto conteúdo energético por unidade de MS.

$\mathrm{Na}$ silagem de milho, a correlação entre produção de forragem por hectare e valor nutritivo não é marcada, indicando que a seleção de plantas para alta produção necessariamente não afeta a digestibilidade por unidade de MS (Fonseca et al., 2002). Na planta de sorgo, existe uma correlação negativa e média entre produtividade e valor nutritivo (Resende et al., 2003). Conhecer a correlação entre a capacidade de produção de MS por hectare, determinante da taxa de lotação animal, e o valor nutritivo da forrageira, determinante da necessidade de alimentos concentrados por unidade de desempenho animal, é necessário na cana-deaçúcar.

Conhecer que características da planta mais se correlacionam com o valor nutritivo tem aplicação prática na escolha dos cultivares em fazendas e pode ser necessário em programas de melhoramento genético de plantas mais desejáveis nutricionalmente. Características altamente correlacionadas também permitem o uso da seleção indireta baseada em características de mais fácil mensuração, potencialmente capaz de reduzir o trabalho e o custo de programas de melhoramento.

Uma característica de dietas formuladas com cana-de-açúcar é a indução de baixo consumo diário, observado mesmo em dietas formuladas para alto desempenho animal (Corrêa et al., 2003). Atuar sobre a digestibilidade da fibra pode ser um caminho para atuar positivamente sobre o consumo (Oba e Allen, 1999). Parece existir variabilidade em digestibilidade da fibra entre cultivares de cana (Molina et al., 1999; Azevedo, 2002; Costa, 2002). É importante compreender a possibilidade de atuação sobre a digestibilidade da fibra da cana e os possíveis impactos de ganhos em qualidade fibrosa sobre a digestibilidade da planta.

Os objetivos deste trabalho foram avaliar a variabilidade de valor nutritivo entre cultivares industriais de cana-de-açúcar e a correlação entre digestibilidade e produtividade da planta, bem como definir que características químicas e agronômicas seriam determinantes do valor nutritivo.

\section{MATERIAL E MÉTODOS}

As canas avaliadas foram cultivadas na Usina Santa Cruz, localizada em Campos dos Goitacazes, RJ, a $21^{\circ} 48^{\prime}$ de latitude Sul, $41^{\circ} 20^{\prime}$ de longitude Norte e a $13 \mathrm{~m}$ de altitude. O clima do município, segundo classificação de Koppen, é AW (IAA/SondoTecnica, 1983). A precipitação anual entre a segunda e a terceira soca, aquela de colheita das plantas, foi de $874 \mathrm{~mm}$, com $65 \%$ de concentração entre os meses de novembro e fevereiro.

Uma amostra de 20 cultivares de cana-de-açúcar foi colhida no mínimo 370 dias após o corte da segunda soca, com Brix superior a 18\%: CB 453, NA 56-79, RB 72454, RB 739359, RB 739735, RB 758540, RB 765418, RB 785750, RB 806043, RB 825336, RB 835089, RB 835486, RB 845257, RB 855035, SP 71-1406, SP 79-1011, SP 79-2233, SP 79-2312, SP 801842 e SP 81-1763. Estas foram cultivadas aleatoriamente dentro de quatro blocos no campo. $\mathrm{O}$ experimento foi instalado em 21/03/1996, e as unidades experimentais foram colhidas a partir de 21/07/2000. As parcelas foram constituídas por quatro linhas de $10 \mathrm{~m}$, com espaçamento de $1,20 \mathrm{~m}$ entre linhas, e as práticas culturais foram as normalmente utilizadas para a cultura da cana-de-açúcar (Zambello e Orlando, 1981).

As características agronômicas foram avaliadas em cada uma das 80 parcelas experimentais e mensuradas em 20 colmos aleatoriamente escolhidos entre os 80 colmos colhidos para estimativa da produção de matéria natural. A produção de matéria natural (ton/ha) foi mensurada após corte a $5 \mathrm{~cm}$ do solo. A porcentagem de MS dos colmos foi determinada por desidratação a $90^{\circ} \mathrm{C}$ por 72 horas. O comprimento do colmo foi definido como a distância em centímetros da base da planta até a extremidade superior do colmo ainda envolta por folhas verdes, restando um colmo totalmente isento de folhas apicais ("olhadura").

O diâmetro do colmo foi mensurado no internódio central do colmo. A densidade do colmo foi determinada pela relação entre o peso e o volume de 10 internódios centrais. O volume foi determinado por imersão em bureta com água destilada. A porcentagem de internódios descobertos foi mensurada imediatamente após a 
colheita. A porcentagem de colmos na planta foi mensurada por separação manual das folhas secas laterais e das folhas verdes apicais. O número de internódios foi mensurado em colmos sem a "olhadura". O número de colmos por metro foi mensurado por contagem de todos os colmos da parcela.

O Brix do caldo foi determinado por leitura em refratômetro tipo Zeiss. O caldo foi extraído de uma amostra de $800 \mathrm{~g}$ de cana. Foi extraída a fibra industrial, e o Brix foi tomado em porcentagem do peso do caldo (Payne, 1968). O Pol foi mensurado no mesmo caldo extraído para determinação do Brix segundo Payne (1968). O teor de açúcares redutores (AR) foi determinado conforme Lane e Eynon (1934).

Cinco plantas inteiras foram aleatoriamente amostradas em cada parcela, trituradas em uma picadeira de forragem e desidratadas em estufa ventilada com temperatura de $55^{\circ} \mathrm{C}$ por 72 horas. Após a pré-secagem, parte das amostras foi moída em peneira de $1 \mathrm{~mm}$ em moinho do tipo Thomas Willey para a realização das análises químicas. O restante da amostra foi moído em peneira de $5 \mathrm{~mm}$ para uso no ensaio de degradabilidade ruminal in situ.

As características químicas analisadas foram porcentagem de MS determinada por secagem da amostra pré-seca a $105^{\circ} \mathrm{C}$, por 24 horas; PB (Association..., 1975); EE (Association..., 1990); cinzas (Association..., 1990); FDN (Van Soest et al., 1991), sem o uso de $\alpha$-amilase, mas com adição de sulfito de sódio; FDA determinada não sequencialmente à FDN (Van Soest et al., 1991); e lignina (Association..., 1975).

Para o estudo da degradabilidade ruminal in situ foram utilizadas seis vacas não lactantes com cânula ruminal, alimentadas com cana-de-açúcar ad libitum e suplementadas com $2 \mathrm{~kg}$ de concentrado comercial à base de milho e farelo de soja (24\% de PB). Amostras de $5 \mathrm{~g}$ de matéria pré-seca foram inseridas em saquinhos de náilon (failet, $100 \%$ poliéster) com dimensões de $9 \times 11 \mathrm{~cm}$, proporcionando uma relação de $50,5 \mathrm{mg} / \mathrm{cm}^{2}$. O resíduo de MS em cada saquinho foi determinado por secagem em estufa ventilada com temperatura de $55^{\circ} \mathrm{C}$ por 72 horas. A degradabilidade ruminal da MS (DEG MS) foi calculada como o desaparecimento de MS em 24 horas de incubação proporcionalmente à MS originalmente incubada. A porcentagem de FDN foi determinada nos resíduos da incubação ruminal, e a degradação da FDN (DEG FDN) foi calculada.

As médias de quadrado mínimo por cultivar, para as características agronômicas e químicas, foram geradas pelo procedimento GLM do SAS (Statistical..., 1995), com um modelo contendo os efeitos de bloco (1 a 4) e cultivar (1 a 20). Para as variáveis descrevendo a DEG MS e a DEG FDN foi acrescido a este modelo o efeito de vaca (1 a 6). Estatísticas descritivas básicas da população (média, DP, valor mínimo e valor máximo) foram geradas a partir das médias de quadrado mínimo por cultivar.

Regressão do tipo Stepwise (Statistical..., 1995) foi utilizada para determinar os melhores modelos de predição da DEG MS e da DEG FDN, tendo as médias de quadrado mínimo das características agronômicas e químicas por cultivar como variáveis independentes. Desde que as variáveis FDN e FDA ( $\mathrm{r}=0,74)$, Pol e Brix $(\mathrm{r}=0,74)$, porcentagem de internódios descobertos e porcentagem de colmo $(\mathrm{r}=0,67)$ e produção de MS e número de colmos por metro $(\mathrm{r}=0,89)$ foram altamente correlacionadas, apenas aquela mais correlacionada à degradabilidade foi utilizada (FDA, Pol, produção de MS e porcentagem de colmo), para evitar problemas de multicolinearidade (Chatterjee e Price, 1991). Foi determinado o melhor modelo de regressão utilizando-se uma variável, duas e assim por diante, até a maximização do coeficiente de determinação. Apenas variáveis independentes com significância abaixo de 0,15 foram incluídas nos modelos. As seguintes variáveis foram consideradas como independentes: produtividade de MS, diâmetro do colmo, comprimento do colmo, porcentagem de colmo, número de internódios, densidade do colmo, Pol, AR, e teores de MS, EE, cinzas, FDA, lignina e PB.

Os coeficientes das correlações genéticas entre a DEG MS e as características comprimento do colmo, FDA e porcentagem de colmo foram estimados segundo Falconer (1996). Com base nas análises de variância geradas pelo procedimento GLM, foram obtidas as estimativas de herdabilidade $\left(\mathrm{h}^{2}\right)$ e seus respectivos intervalos de confiança para cada variável segundo Knapp et al. (1985). A $\mathrm{h}^{2}$ foi estimada como o quadrado médio para o efeito de cultivar 
subtraído do quadrado médio para o erro experimental, proporcionalmente ao quadrado médio para o efeito de cultivar.

O ganho potencial em DEG MS a aumento na DEG FDN foi estimado. A equação de regressão quantificando a resposta em DEG MS por unidade de aumento na DEG FDN foi realizada após ajuste para uma porcentagem constante de FDN na cana-de-açúcar. Para tal, a DEG MS foi utilizada como variável dependente em um modelo contendo a porcentagem de FDN na planta e a DEG FDN, nesta ordem, como variáveis independentes. A regressão foi executada pelo procedimento GLM do Statistical... (1995), e o valor de probabilidade do Tipo I para a inclinação da reta quantificando a resposta em DEG MS à variação na DEG FDN foi avaliado.

\section{RESULTADOS E DISCUSSÃO}

A produtividade média dos 20 cultivares de cana-de-açúcar foi alta quando comparada à de outras forrageitas. A produção de MS por hectare de 18 híbridos de sorgo avaliados por Resende et al. (2003) foi de 13t, cerca de $60 \%$ da produtividade média dos cultivares de cana em final de vida útil neste trabalho (Tab. 1). A produtividade de MS do milho, cultivado simultaneamente aos híbridos de sorgo acima referidos, foi 16t/ha (Fonseca et al., 2002). A cana-de-açúcar é uma opção quando a meta é maximizar a taxa de lotação animal em sistemas de produção baseados em plantas tropicais com alto conteúdo energético.

É possível, entretanto, a obtenção de produtividades pouco competitivas na cana-deaçúcar, já que alguns cultivares tiveram produtividade em torno de 10t/ha (Tab. 1). O coeficiente de variação na produtividade foi de $27 \%$, superior a valores observados para o milho, ao redor de 12\% (Fonseca et al., 2002), e, para o sorgo, ao redor de $18 \%$ (Resende et al., 2003). Apesar de a produtividade ser afetada por determinantes ambientais, como tratos culturais e ano de corte após o plantio, $65 \%$ da variação observada foi de natureza genética nesta população de plantas (Tab. 1). Valores de $\mathrm{h}^{2}$ para a característica produtividade variando de $26 \%$ a $86 \%$ têm sido relatados para a cana-de-açúcar, sendo que o valor médio de seis trabalhos foi de
66\% (Brown et al., 1968; Mariotti, 1971; Mariotti, 1973; Zacarias, 1977; Skinner, 1987; Bressiane, 2001), enfatizando a importância da genética para se obter alta produtividade na cana.

Não foi evidenciada uma forte correlação entre produtividade e DEG MS (Fig. 1). Caso a seleção para alto valor nutritivo implicasse a necessidade de queda na produtividade, a utilização da DEG MS como critério de seleção de canas forrageiras poderia ser questionada. Entretanto, existem canas que conciliam a alta produtividade com o alto valor nutritivo. Programas de melhoramento, com meta no desenvolvimento de alta digestibilidade por unidade de MS, necessariamente não penalizam a produção por unidade de área. Parece ser plausível a meta de maximizar animais por hectare e, ao mesmo tempo, minimizar o gasto com alimentos concentrados por unidade de desempenho animal, em sistemas de produção que adotam a cana-de-açúcar.

A DEG MS foi, em média, 57,1\% da matéria seca, com coeficiente de variação de 4,6\% (Tab. 1). O coeficiente de variação da PMS foi cerca de cinco vezes superior a este valor, evidenciando a menor variabilidade no caráter digestivo proporcionalmente à produtividade nesta população de cultivares (Fig. 1). Pate e Coleman (1975) avaliaram 66 cultivares comerciais de cana-de-açúcar no sul da Flórida e observaram que a digestibilidade in vitro da matéria orgânica foi $56,6 \% \pm 4,5 \%$, variando de $40,0 \%$ a $64,1 \%$. Molina et al. (1999) avaliaram 74 cultivares de cana em Cuba e encontraram valores de degradabilidade in situ da MS em 48h

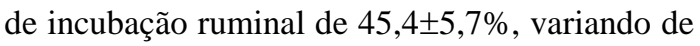
$34,3 \%$ a $57,4 \%$. Existe variabilidade em digestibilidade da MS na cana-de-açúcar.

A seleção direta para a variável DEG MS parece ser a mais indicada, pois esta teve valor de $h^{2}$ superior a 85\% (Tab. 1). Gomes (2003), ao avaliar 36 linhagens de milho em duas épocas de plantio, encontrou valor de $\mathrm{h}^{2}$ para a DEG MS de $80,4 \%$. Parece ser plausível que sejam preconizados programas de melhoramento genético específicos para o desenvolvimento de forrageiras mais adequadas nutricionalmente. 
Tabela 1. Médias, desvios-padrão (DP), valores mínimos (Mín) e máximos (Máx) e herdabilidade $\left(h^{2}\right.$ ) com limite inferior (LI) e superior (LS) do intervalo de confiança para características químicas e agronômicas em uma população de 20 cultivares de cana-de-açúcar

\begin{tabular}{|c|c|c|c|c|c|c|c|}
\hline Características ${ }^{(1)}$ & Média & DP & Mín & Máx & $\mathrm{h}^{2}(\%)$ & LI & LS \\
\hline PMN (t/ha) & 68,3 & 15,83 & 32,3 & 112,7 & 55,1 & 11,2 & 80,3 \\
\hline PMS (t/ha) & 21,2 & 5,67 & 10,4 & 39,2 & 65,4 & 31,5 & 84,2 \\
\hline MS (\% da MN) & 30,9 & 1,35 & 28,6 & 34,9 & 29,8 & $-39,1$ & 69,2 \\
\hline $\operatorname{DiamC}(\mathrm{cm})$ & 2,53 & 0,12 & 2,29 & 2,85 & 58,3 & 17,3 & 81,7 \\
\hline CompC $(\mathrm{cm})$ & 189,0 & 14,42 & 165,5 & 223,0 & 41,4 & $-16,2$ & 74,7 \\
\hline Colmet (n/m) & 18,4 & 3,76 & 12,9 & 24,2 & 71,8 & 35.80 & 85,8 \\
\hline Pcolmo (\% da MS) & 81,7 & 3,76 & 75,8 & 87,1 & 63,1 & 26,9 & 83,8 \\
\hline Intern (n/colmo) & 14,3 & 1,28 & 12,2 & 16,7 & 62,2 & 25,1 & 83,4 \\
\hline PID (\% no colmo) & 25,1 & 16,77 & 4,5 & 60,2 & 82,8 & 65,8 & 92,4 \\
\hline DensC (g/mL) & 0,92 & 0,05 & 0,80 & 1,01 & 0,00 & - & - \\
\hline AR ( $\%$ do caldo) & 1,08 & 0,24 & 0,68 & 1,60 & 65,2 & 20,8 & 82,5 \\
\hline Pol (\% da cana) & 14,2 & 0,77 & 13,0 & 15,8 & 50,2 & 13,5 & 74,8 \\
\hline Brix (\% do caldo) & 19,7 & 0,74 & 17,9 & 21,1 & 42,9 & $-13,1$ & 74,9 \\
\hline $\mathrm{EE}(\%$ da MS) & 1,5 & 0,42 & 1,1 & 2,6 & 18,8 & $-60,8$ & 64,4 \\
\hline Cinzas (\% da MS) & 4,5 & 0,64 & 2,7 & 5,3 & 48,2 & $-2,7$ & 77,7 \\
\hline PB (\% da MS) & 4,0 & 0,52 & 3,2 & 5,2 & 55,4 & 11,8 & 80,4 \\
\hline Lignina (\% da MS) & 6,2 & 0,58 & 5,0 & 7,0 & 0,00 & - & - \\
\hline FDA ( $\%$ da MS) & 30,9 & 1,77 & 28,0 & 34,6 & 19,5 & $-59,4$ & 64,6 \\
\hline FDN (\% da MS) & 49,2 & 2,53 & 42,8 & 52,7 & 23,3 & $-52,0$ & 66,3 \\
\hline DEG MS (\% da MS) & 57,1 & 2,64 & 52,6 & 61,6 & 87,9 & 78,6 & 94,3 \\
\hline DEG FDN ( $\%$ da FDN) & 19,8 & 2,42 & 16,7 & 26,0 & 0,0 & - & - \\
\hline
\end{tabular}

${ }^{(1)}$ Produtividade de matéria natural (PMN), produtividade de matéria seca (PMS), porcentagem de matéria seca na planta (MS), diâmetro do colmo (DiamC), comprimento do colmo (CompC), número de colmos por metro (Colmet), porcentagem de colmo (Pcolmo), número de internódios (Intern), porcentagem de internódios descobertos (PID), densidade do colmo (DensC), açúcares redutores (AR), sacarose (Pol), açúcares totais (Brix), extrato etéreo (EE), proteína bruta (PB), fibra em detergente ácido (FDA), fibra em detergente neutro (FDN), degradabilidade da MS (DEG MS) e da FDN (DEG FDN).

Três modelos foram gerados tendo a DEG MS como variável dependente (Tab. 2). Utilizou-se na análise apenas a variável mais correlacionada à DEG MS, a FDA $(\mathrm{r}=-0,83, \quad P<0,01)$. A correlação entre a DEG MS e a FDA foi 0,05 superior à correlação com a FDN. Este fato é comum na literatura e tem sido explicado pela maior participação proporcional da lignina indigestível no resíduo de filtragem após digestão em detergente ácido comparativamente à participação deste composto no resíduo do detergente neutro (Van Soest, 1994). A lignina é proporcionalmente um maior participante da
FDA que da FDN, já que apenas o segundo inclui a hemicelulose.

Semelhantemente ao observado nas silagens de milho ou sorgo (Fonseca et al., 2002; Resende et al., 2003 ), o teor de fibra foi o maior determinante da degradabilidade da cana no rúmen (Fig. 2). Quanto maior o conteúdo de carboidratos de degradação lenta, menor a degradabilidade ruminal da forragem. Relatos da correlação entre os teores de fibra e a degradação da MS no rúmen são altos, negativos e similares numericamente às estimativas deste trabalho (Pate e Coleman, 1975; Costa, 2002). 


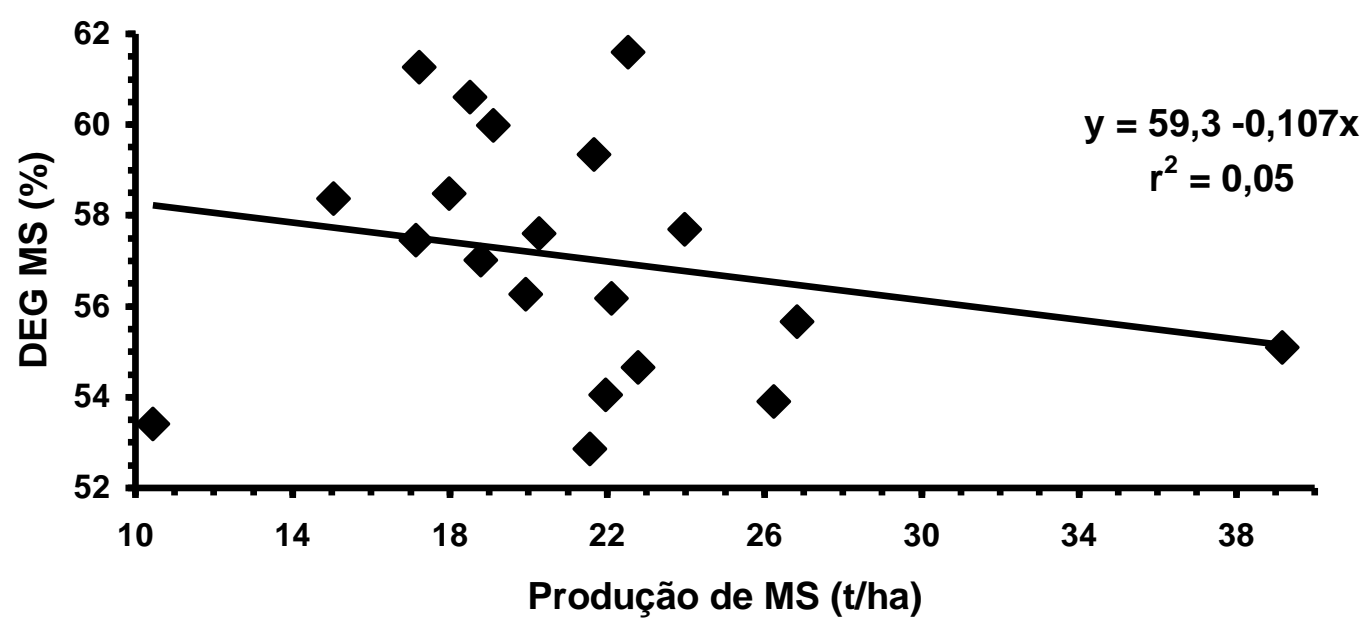

Figura 1. Correlação entre a produção de matéria seca (MS) por hectare e a degradabilidade ruminal da MS (DEG MS) em 20 cultivares de cana-de-açúcar.

Tabela 2. Equações geradas por regressão do tipo Stepwise descrevendo a variação na degradabilidade ruminal da matéria seca (DEG MS) de cultivares de cana em função de variação nas características químicas e agronômicas da planta

\begin{tabular}{lcc}
\hline Modelos $^{(1)}$ & $\mathrm{R}^{2}$ & $P$ \\
\hline DEG MS $=95,32-1,238($ FDA $)$ & 0,70 & $<0,01$ \\
DEG MS $=100,80-0,452($ CompC) $-1,140$ (FDA) & 0,75 & 0,07 \\
DEG MS $=83,46-0,052($ CompC) $+0,179$ (Pcolmo) $-1,009$ (FDA) & 0,81 & 0,04 \\
\hline
\end{tabular}

${ }^{(1)}$ Comprimento do colmo (CompC. $\mathrm{cm}$ ), porcentagem de colmo (Pcolmo. \% da MS), fibra em detergente ácido (FDA. \% da MS).

A meta primordial para a obtenção de canas de alto valor nutritivo parece ser a redução no teor de fibra da forragem. Entretanto, obter redução no teor de FDN ou FDA da cana-de-açúcar por artifícios genéticos não se mostrou uma estratégia promissora. Essas características foram pouco variáveis nessa população de plantas e apresentaram estimativas de $\mathrm{h}^{2}$ médias e com alto intervalo de confiança, inclusive com limite mínimo negativo (Tab. 1). O teor de fibra da cana parece ser mais determinado por fatores ambientais, como tratos culturais e época de colheita relativamente à maturidade da planta, por exemplo. Tal fato sugere que vários cultivares desenvolvidos para a indústria sucroalcooleira podem ser eficientes nutricionalmente, desde que adequadamente manejados para terem alto teor de sacarose, o que é inversamente relacionado ao teor de fibra na MS. Não há relatos na literatura de estimativas de $h^{2}$ para as características teor de FDN e FDA da cana-de-açúcar.
O segundo item mais importante na degradabilidade da cana-de-açúcar no rúmen foi o comprimento dos colmos (Tab. 2). Canas de alta digestibilidade tiveram colmos mais curtos. Entretanto, a correlação entre o comprimento do colmo e a produtividade foi de $0,44 \quad(P<0,05)$. Buscar ganho em digestibilidade por atuação sobre o comprimento dos colmos pode induzir perda de produtividade, sendo incoerente ao potencial da cana de propiciar alta lotação animal por hectare.

A terceira melhor equação foi formada acrescentando a porcentagem de colmos ao Modelo 2 (Tab. 2). Canas com maior porcentagem de colmos, ou seja, baixa relação entre palhas e folhas, foram mais digestíveis. Isso se explica pelo fato de a sacarose de alta digestibilidade estar contida nos colmos, enquanto a parte vegetativa é rica em fibra de baixa digestibilidade. A digestibilidade in vitro da MS de folhas em 11 cultivares de cana foi 
$51,39 \% \pm 4,09$, enquanto a digestibilidade dos colmos foi $75,45 \% \pm 2,98$ (Rodrigues et al., 1997). A proporção de colmos tem sido preconizada como critério para seleção de canas para alimentação animal. Rodrigues et al. (1997) sugerem que canas mais desejáveis teriam proporção de colmos na planta superior a $80 \%$. A definição de um limite mínimo neste parâmetro requer mais experimentação, mas, entre os 20 cultivares aqui estudados, 12 apresentavam proporção de colmos superior a $80 \%$.

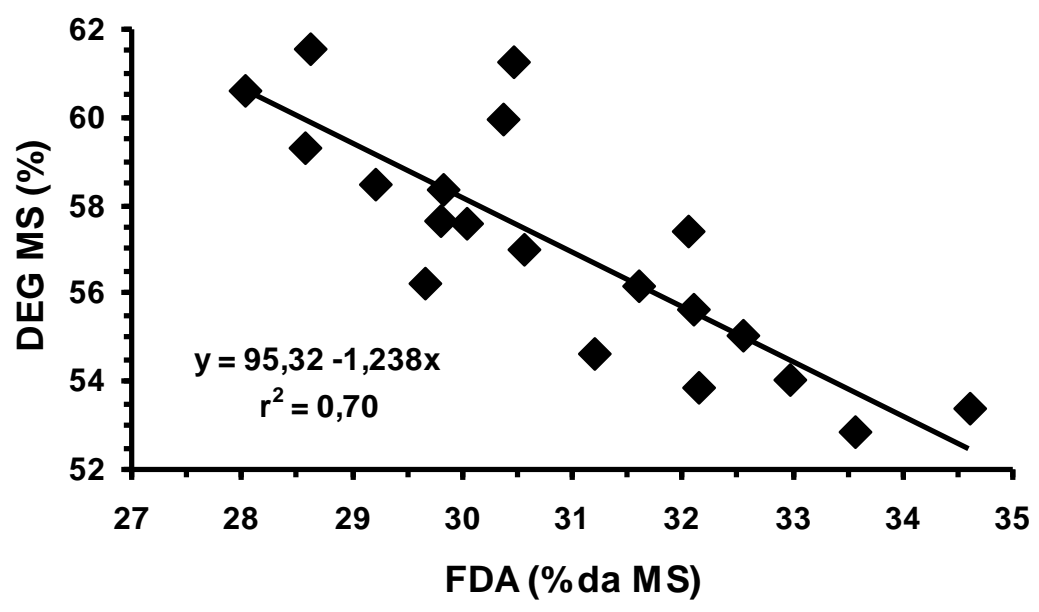

Figura 2. Correlação entre a degradabilidade ruminal da matéria seca (DEG MS) e a porcentagem de fibra em detergente ácido (FDA) em 20 cultivares de cana-de-açúcar.

A correlação entre a porcentagem de colmos e a produtividade de MS por hectare não foi significativa ( $\mathrm{r}=-0,21, P>0,10)$. Estes dados não suportam o conceito de que canas com alto teor de folhas seriam desejáveis como forrageiras por terem maior produtividade, um conceito esporadicamente disseminado. Além das vantagens nutricionais, canas com alta proporção de colmo e baixa proporção de folhas e palhas seriam vantajosas operacionalmente por facilitarem a colheita, o transporte e a moagem da forragem na fazenda. Redução na proporção de folhas na planta poderia ser obtida por melhoramento genético (Tab. 1), despalha manual ou por queima. Entre as três características mais correlacionadas ao valor nutritivo, a porcentagem de colmos foi a mais herdável $\left(\mathrm{h}^{2}=63,1 \%\right)$.

A correlação genética entre a DEG MS e a porcentagem de colmos, o comprimento do colmo e o teor de FDA foram 0,58, -0,71 e -1,81, semelhantes às correlações fenotípicas, 0,45 , 0,45 e $-0,83$, respectivamente. A similaridade numérica entre estas estimativas sugere que tanto os fatores genéticos como os ambientais se associam de modo semelhante na expressão conjunta dessas características. A correlação genética superior a 1 obtida entre a FDA e a DEG MS não é esperada, contudo ela ocorre em razão do erro associado à estimativa; nesse caso, provavelmente devido à menor precisão na avaliação da FDA, já que a herdabilidade para essa característica foi pequena (Tab. 1).

A DEG FDN não se correlacionou a qualquer das variáveis estudadas e apresentou $\mathrm{h}^{2}$ nula (Tab. 1). Não há relatos de outras estimativas de $h^{2}$ para esta característica na literatura. Nenhuma variável apresentou significância inferior a 0,15 , necessária para ser incluída no modelo de regressão multivariada do tipo Stepwise para a DEG FDN. O uso de qualquer variável correlacionada para inferências quanto à degradabilidade da fibra da cana-de-açúcar não mostrou ser promissor. A variabilidade em DEG FDN dentro desta população de canas industriais pode não ter sido suficientemente alta para apontar relacionamentos significativos.

A DEG FDN foi em torno de $20 \%$ (Tab. 1), valor rotineiramente relatado na literatura (Molina et al., 1999; Costa, 2002). Apesar de a variação de 10 unidades percentuais na DEG FDN ser um 
valor aparentemente significativo, seu efeito sobre a DEG MS não foi marcado, já que a correlação entre estes fatores foi de apenas 0,34 $(P>0,10)$. Para estimar o ganho potencial em DEG MS por atuação sobre a DEG FDN, foi gerada uma regressão avaliando o efeito do aumento na DEG FDN, dentro da amplitude de valores observados experimentalmente, após ajuste para o teor de FDN da cana média $(49,2 \%$ da MS). A equação foi: DEG MS = 89,7 - 0,807 (FDN. \% da MS) + 0,358 (DEG FDN. \% da FDN). O valor de $P$ Tipo I foi 0,02 . Se houvesse disponibilidade de uma cana com 49,2\% de FDN, o ganho estimado na DEG MS seria de 4 unidades percentuais caso a digestibilidade desta FDN no rúmen fosse aumentada de $16 \%$ para $26 \%$ do incubado.

O teor de lignina nas canas (Tab. 1) foi semelhante ao da silagem de milho e metade do teor observado na alfafa (National..., 2001). A porcentagem de lignina na planta é sabidamente um preditor imperfeito da digestibilidade entre espécies forrageiras, a localização dos tecidos lignificados na planta parece ser mais determinante da digestibilidade que o teor deste constituinte (Akin e Robinson, 1982). Nesta população de canas, não se detectou qualquer associação entre lignina e as estimativas de degradabilidade ruminal. Não existe informação básica sobre os fatores intrínsecos à cana-deaçúcar determinantes da baixa digestibilidade da fibra, típica desta forrageira. A porcentagem de lignina apresentou $h^{2}$ zero (Tab. 1), provavelmente devido à ausência de variabilidade na característica, o que também explicaria a ausência de correlação com todas as variáveis estudadas, com exceção da FDA $(\mathrm{r}=0,44, \quad P<0,05)$. A razão para a baixa digestibilidade da fibra da cana no rúmen requer maior consideração científica.

\section{CONCLUSÕES}

Nos cultivares de cana-de-açúcar avaliados, a variabilidade em produtividade foi maior que a variabilidade em digestibilidade. Almejar ganho em digestibilidade parece não ser antagônico à meta de se obter alta produtividade. Entre as variáveis químicas e agronômicas avaliadas, a mais correlacionada à digestibilidade foi o teor de fibra na planta. Canas que, além do baixo teor de fibra, também apresentaram alta relação entre colmos e folhas, parecem ser mais desejáveis nutricionalmente.

\section{REFERÊNCIAS}

AKIN, D.E.; ROBINSON, E.L. Structure of leaves and stems of arrow leaf and crinson clovers as related to in vitro digestibility. Crop Sci., v.22, p.24-29, 1982.

ASSOCIATION OF OFFICIAL AGRICULTURAL CHEMISTS. Official methods of analysis of the Association of Official Agricultural Chemistry. 12.ed. Washington, 1975. v.1. 1094p.

ASSOCIATION OF OFFICIAL AGRICULTURAL CHEMISTS. Official methods of analysis of the Association of Official Agricultural Chemistry. 15.ed. Virginia, 1990. v.1, 684p.

AZEVEDO, J.A. Avaliação nutricional de variedades de cana-de-açúcar (Saccharum sp.) e simulação do desempenho de vacas leiteiras. 2002. 90f. Dissertação (Mestrado em Zootecnia) - Universidade Federal de Lavras, Lavras.

BRESSIANE, J.A. Seleção seqüencial em canade-açúcar. 2001. 104f. Tese (Doutorado) Escola Superior de Agricultura Luiz de Queiroz, Piracicaba.

BROWN, A.H.D.; DANTELS, J.; LATTER, B.D.H. Quantitative genetics of sugarcane. I Analysis of variation in commercial hybrid sugarcane population. Theor. Appl. Gen., v.38, p.361-369, 1968.

CHATTERJEE, S.; PRICE, M.N. Regression analysis by example. New York: John Wiley \& Sons, 1991. 278p.

CORRÊA, C.E.S.; PEREIRA, M.N.; RAMOS, M.H. Performance of Holstein cows fed sugarcane or corn silages of different grain textures. Sci. agric., v.60, p.621-629, 2003.

COSTA, H.N. Efeito do ambiente ruminal sobre a degrabilidade in situ da cana-de-açúcar. 2002. 51f. Dissertação (Mestrado em Zootecnia) Universidade Federal de Lavras, Lavras.

FALCONER, D.S.; MacKAY, T.F.C. Introduction to Quantitative Genetics. Longman, 1996. 464p.

FONSECA, A.H.; VON PINHO, R.G.; PEREIRA, M.N. et al. Características agronômicas, químicas e nutricionais de híbridos de milho visando a produção de silagem de alto valor nutritivo. Rev. Ceres, v.49, p.41-54, 2002. 
GOMES, M.S. Valor genético de linhagens de milho na produção e digestibilidade da silagem. 2003. 135f. Tese (Doutorado em Agronomia) Universidade Federal de Lavras, Lavras.

IAA/SONDOTÉCNICA. Rio de Janeiro. Projeto de irrigação e drenagem da cana-de-açúcar na região Norte Fluminense. Estudos de climatologia, relatório técnico setorial. Rio de Janeiro: 1983. v.1, 102p.

KNAPP, S.J.; STROUP, W.W.; ROSS, W.M. Extract confidence intervals for heritability on a progeny mean basis. Crop Sci., v.25, p.192-194, 1985.

LANE, J.H.; EYNON, L. Determination of reducing sugar by Fehling's solution with methylene blue indication. London, Norman Rodger. 1934. 8p.

MARIOTTI, J.A. Estimaciones de herdabilidade en parcelas clonales en cinco poblaciones híbridas de caña de azúcar. Rev. Agron. N.O. Argent., v.8, p.373-389, 1971.

MARIOTTI, J.A. Experiencias de selección clonal en caña de azúcar en la provincia de Jujuy. II. Repetibilidad y heredabilidad de caracteres de interesses agronomico. Rev. Agron. N.O. Argentina, v.10, p.61-73, 1973.

MOLINA, A. Forage evaluation of sugar cane industrial varieties. In situ digestibility. Cuban J. Agri. Sci., v.33, p.369-373, 1999.

NATIONAL RESERCH COUNCIL - NRC Nutrient requirements of dairy cattle. 7.ed. Washington: National Academy Press, 2001.

OBA, M.; ALLEN, M.S. Evaluation of the importance of the digestibility of neutral detergent fiber from forage: effects on dry matter intake and milk yield. J. Dairy Sci., v.82, p.589596, 1999.

PATE, F.M.; COLEMAN, S.W. Evaluation of sugarcane varieties as cattle feed. Flórida: University of Fla., n.4, 1975. 8p.

PAYNE, J.H. Sugar Cane Factory Analytical Control. New York: Elsevier Publishing Co., 1968. 190p.
PRESTON, T.R.; LENG, R.A. Utilization of tropical feeds by ruminants. In: RUCKEBUSCH, Y.; THIEVEND, P. Digestive physiology and metabolism in ruminants. Connecticut: AVI, 1980. 359 p.

RESENDE, J.A.; PEREIRA, M.N.; PINTO, R.V.G. et al. Ruminal silage degradability and productivity of forage and grain-type sorghum cultivars. Sci. Agric., v.60, p.457-463, 2003.

RODRIGUES, A.A. Efeito da qualidade de variedades de cana-de-açúcar sobre o seu valor nutritivo como alimento para bovinos. Pesq. Agrop. Bras., v.32, p.1333-1338, 1997.

STATISTICAL Analysis Sistem. SAS INSTITUTE. SAS ${ }^{\circledR}$ User's guide: Statistics. Cary, NC, 1995.1290p.

SKINNER, J.C. Selection methods, criteria, and indices. In: HEINS, D.J. (Ed.) Sugarcane improvement through breeding. Amsterdam: Elsevier, 1987. p.409-453.

VAN SOEST, P.J. Nutritional ecology of the ruminant. 2.ed. Ithaca: Cornell University Press, 1994, p.476.

VAN SOEST, P.J.; ROBERTSON, J.B.; LEWIS, B.A. Methods for dietary fiber, neutral detergent fiber, and nonstarch polysaccharides in relation to animal nutrition. J. Dairy Sci., v.74, p.35833597, 1991.

ZACARIAS, C.A.B. Estimação de parâmetros genéticos e fenotípicos em clones de cana-deaçúcar (Saccharum ssp.) e suas implicações no melhoramento 1977. 77f. Dissertação (Mestrado em Genética e Melhoramento de plantas) Escola Superior de Agricultura Luiz de Queiroz, Piracicaba.

ZAMBELLO Jr., E.; ORLANDO FILHO, J. Adubação de cana-de-açúcar na região CentroSul do Brasil. Bol. Téc. Planalsucar, v.3, p.1-26, 1981. 